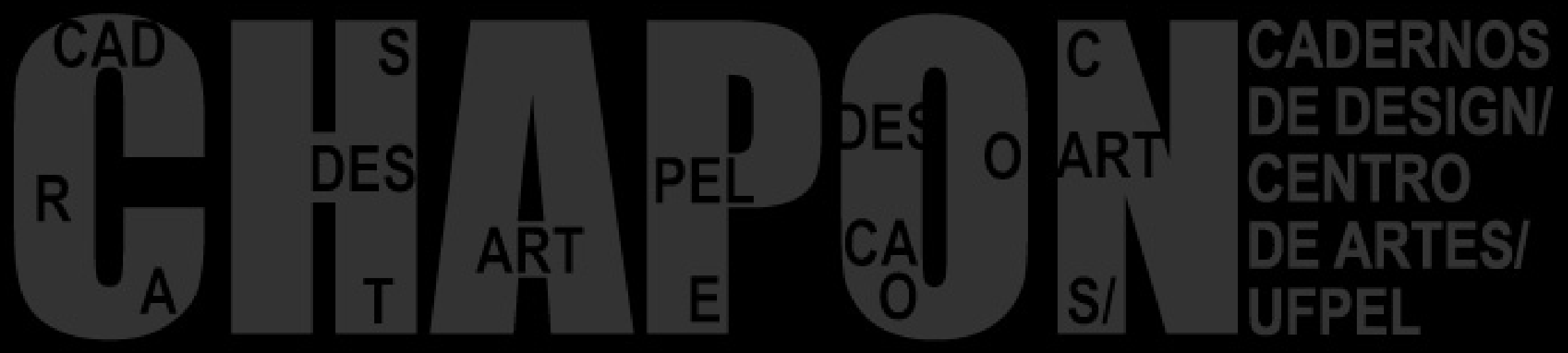

LINGUAGENS METODOLOGIAS TEORIAS VISUALIDADES 


\section{DESIGN SOCIAL: OBJETOS BIOGRÁFICOS DO COTIDIANO, MEMÓRIA SOCIAL}


O artigo apresenta uma reflexão sobre a leitura e releitura de objetos biográficos, lembranças de família e as histórias e possíveis estórias que trazem valores intangíveis para objetos, valores repassados de uma geração à outra. Objetos que falam a respeito das experiências de construção afetiva do passado. Busca-se investigar e identificar alguns objetos relacionados à vida humana em contexto urbano e relatar a passagem desses objetos na história contemporânea. Os bens que conservamos durante décadas podem ser considerados espelhos de nossas experiências da passagem do tempo. A metodologia da pesquisa, após as revisões bibliográficas, analisa os termos utilizados no estudo, como: design para a inovação social;cultura, identidade e memória; pertencimento e o valor sustentável do guardar e cuidar. Em um estudo de caso, no município de Matozinhos, observam-se os eventos culturais, personagens locais e o patrimônio. Após seleção do grupo de estudo, são realizadas palestras e oficinas sobre a memória cultural e o patrimônio material e imaterial da região, para jovens e adultos. Entre os resultados, registram-se a relação da comunidade com os eventos culturais e o desenvolvimento de produtos artesanais. Verifica-se um potencial de valorização da cultura por meio da memória cultural relacionada aos objetos.

Palavras-chave: Design social; objetos biográficos; memória social; comunidade.
The article presents a reflection on the reading and re - reading of biographical objects, family memories and the stories and possible stories that bring intangible values to objects, values transferred from one generation to another.

Objects that speak about past affective building experiences. It seeks to investigate and identify some objects related to human life in urban context and to report the passage of these objects in contemporary history. The goods we have conserved for decades can be considered mirrors of our experiences of the passage of time. The methodology of the research, after the bibliographic reviews, analyzes the terms used in the research as: design for social innovation; culture, identity and memory; belonging and the sustainable value of saving and caring. In a case study, in the municipality of Matozinhos, we observe the cultural events, local characters and the patrimony. After selection of the study group, lectures and workshops on cultural memory and material and immaterial heritage of the region are held for young people and adults. Among the results, the community's relationship with cultural events and the development of artisanal products are recorded. There is a potential for appreciation of culture, through cultural memory related to objects.

Keywords: Social design; biographical objects; social memory; community. 
1.

INTRODUÇÃO
Em ambientes urbanos, a vida contemporânea é cercada de objetos pouco tangíveis e imemoráveis, que podem dificultar a compreensão dos valores socioculturais e das relações emocionais, como o prazer e a felicidade. Os objetos biográficos são aqueles que representam as experiências humanas de construção afetiva do passado. Podem ser citadas as fotografias, uma santinha de cabeceira, uma caixinha de música, uma escova de cabelo, uma penteadeira, um castiçal, os vidros de perfume, ou seja, aqueles objetos guardados em um lugar de significação para a pessoa. O que diferencia esses objetos de tantos outros são os valores histórico e emocional a ele destinados, contidos na memória familiar ou individual. São chamados objetos biográficos porque recordam pessoas ou momentos de suas vidas e fazem parte do contexto histórico de cada indivíduo, conforme Bosi (1979).

Busca-se investigar e identificar alguns objetos relacionados à vida humana em contexto urbano e relatar a passagem desses objetos na história contemporânea. As marcas de vivência podem acrescentar autoridade a um objeto, como aquelas depressões na superfície de um bufê ou de um bibelô. São objetos que ajudam a perpetuar o passado e a construir narrativas a respei- to da trajetória de vida daqueles que o preservaram. Os bens que conservamos durante décadas podem ser considerados espelhos de nossas experiências da passagem do tempo.

Em função do consumismo atual, muitos produtos ingressam na vida das pessoas, em suas moradias, por relações efêmeras e modismo, que proporcionam ao consumidor uma sensação de prestígio e completude. "Agora a relação com os novos bens parece mais vazia. A atração de um produto é criada e vendida na base de um olhar que não sobrevive ao contato físico. A atração se esvazia tão depressa que a paixão acaba quase logo a venda é realizada. O desejo fenece muito antes que o objeto envelheça" (SUDJIC, 2010, p. 18). Dessa forma, esvazia-se a emoção da herança, do poder usar e revisar a função e sua ocupação espacial de um produto. "Um número excessivo de coisas no mundo são projetadas, construídas e nos são impingidas sem nenhuma compreensão e conhecimento ou mesmo preocupação com relação a como as usamos" (NORMAN, 2006, p. 7).

A função do design perpassa pela criação de produtos cada vez mais úteis, bons, bonitos, baratos e eficazes, como aponta Norman em "O Design do Dia-a-dia". Ele também reflete sobre o que Maeda apontou como a simplicidade, a criação de produtos pelo desejo e consumo, por mudanças exageradas de formas, funções mais complexas, que geram problemas desnecessários e insanos, "paradoxos" e "pecados" do design moderno, segundo Norman (2006). 
Pensar em como as pessoas lidam com numerosos objetos e estruturas espaciais que povoam suas vidas cotidianas, o que estes objetos comunicam, e como refletem a sua função principal de se aproximarem do usuário, são algumas questões dessa pesquisa. Busca-se ainda, explorar a presença desses objetos e memórias relacionadas com a comunidade.

Para avaliar o valor de uso de um objeto é preciso saber a extensão, referente à sua funcionalidade, de sua capacidade de satisfazer as expectativas das pessoas. Marx (1980) diz que a utilidade de um objeto é proporcional ao seu valor de uso, e este só se concretiza com a utilização ou o consumo. O valor de estima depende da interpretação, ou seja, está relacionado à semântica.

Krippendorff (1990) diz que o significado de algo não reside na sua superfície, emerge no uso, no cotidiano, na prática de viver o ambiente e contextos específicos. Os significados construídos pelo uso dos seres humanos estão apoiados no modo de viver de cada grupo social. Penetram pela superfície até as profundezas em que o conhecimento pode chegar envolvendo a capacidade cognitiva: quanto mais interação houver com o objeto maior o significado.

Em atividades do design para a inovação social, as desigualdades podem ser minimizadas e valores podem ser resgatados ou aferidos. As ações podem, inclusive, servir para melhor compreensão das transformações sociais que vivemos atualmente, onde o design está inserido. É cada vez mais necessária a intervenção do designer para alcançar uma melhor relação produto - ambiente - sociedade, e isto inicialmente pode ser atingido com a formação de uma cultura de designers conscientes dos problemas sociais e dos impactos ambientais (MANZINI, 2008).

Neste sentido, os designers podem ter um papel muito especial e, esperamos, importante: mesmo não tendo meios para impor sua própria visão aos outros, possuem, porém, os instrumentos para operar sobre a qualidade das coisas e sua aceitabilidade e, portanto, sobre a atração que novos cenários de bem-estar possam porventura exercer. Seus papéis específicos na transição que nos aguarda é oferecer novas soluções a problemas, sejam velhos ou novos, e propor seus cenários como tema em processos de discussão social, colaborando na construção de visões compartilhadas sobre futuros possíveis e sustentáveis (MANZINI, 2008, p. 16).

A pesquisa inicial é de caráter documental e bibliográfico, tem caráter exploratório e será desenvolvida conjugando estudos bibliográficos aprofundados e de campo, em uma abordagem de análise qualitativa e análise dos dados. Limitada ao município de Matozinhos, terá como principal fonte de pesquisa as imagens que documentam as intervenções já realizadas na cidade ao longo de seu desenvolvimento e expansão. A definição das atividades é realizada em parceria com a comunidade. Realiza-se análise de entrevistas abertas e resultados de produtos em oficinas de produção artesanal. 


\section{2.}

DESIGN

PARA A

INOVAÇÃO

SOCIALE

SUSTENTA-

BILIDADE
Design para a inovação social e sustentabilidade tem várias definições e o termo é empregado em contextos diversos em todo o mundo. Algumas definições existem pautadas com a palavra design como forma dos produtos e serviços, outras definições referem-se ao design como inspiração da realidade, design do mundo social. Papanek (1977) relata que é preciso priorizar requisitos sociais, que devem ser destacados em todos os níveis do processo de desenvolvimento e produção, visando obter produtos que causem uma melhoria na qualidade de vida das pessoas.

Papanek (1977) abre um debate sobre o papel e a representação do design, que deve ser orientada para as necessidades e não para as vontades do Homem. Design responsável toma várias direções e uma dessas é trabalhar para o 'Terceiro Mundo'. O autor conduz para a reflexão de que o Design social é inspirado por ideias de forma responsável.

Dentro do universo do design para a inovação social e sustentabilidade, o design social é às vezes definido como um artifício que contribui para o melhoramento do ser humano. Design social é uma abordagem de projeto que implica tanto metodologias participativas como motivações projetuais e consequências sociais do processo de design. É possível afirmar ainda que o design social também promova valores como sustentabilidade e desenvolvimento sociocultural, como aponta Braga (2011).

O design social, de acordo com Löbach (2001), trata de uma questão ética e social orientada pelos problemas da sociedade e tem como meta a melhoria das condições de vida de determinados grupos, colocando os problemas do usuário como centro das atenções no projeto, respeitando o meio ambiente, a cultura como valor agregado e privilegiando a mão de obra local.

Cipolla (2008), relacionando inovações à sustentabilidade, apresenta as declarações de Manzini, ao colocar a sustentabilidade como meta-objeto de todas as possíveis pesquisas em design. Ou seja, não deveria ser um setor especializado, que corre paralelo a outros setores especializados, mas parte do processo. Provavelmente, ninguém discorda, pois nenhum produto quer ser insustentável.

O termo 'deveria ser' indica que tal objetivo não foi atingido, sendo, portanto, ainda necessário considerar o design 'para a sustentabilidade' como um setor especifico, englobando todos os passos concretos que os designers podem conscientemente dar rumo a um futuro sustentável. Manzini indica que esses passos devem ter um caráter sistêmico e o design, para colocá-los em prática, deve possuir um forte artifício estratégico. Assim sendo, em súmula, o design para a sustentabilidade é o design estratégico capaz de colocar em ato descontinuidades locais promissoras, contribuindo para efetivas mudanças sistêmicas (CIPOLLA, 2008, p. 12). 
Considerando a busca da sustentabilidade como parte do projeto, verificam-se os pilares para a tomada de decisões do design social, de forma participativa: primeiro manter o foco no cidadão (participante do processo produtivo, agente influenciador ou influenciado pelos resultados do processo); em segundo, inserir os principais agentes sociais deste processo nas tomadas de decisões; e por último, ter como meta final a inclusão de todos estes agentes envolvidos, produtiva, social ou economicamente.

Estudos realizados durante a execução do Programa Comunidades Criativas das Gerais, do Centro de Estudos em Design e Tecnologia da Escola de Design - Universidade do Estado de Minas Gerais, identificaram as questões que se fundamentam nas avaliações do design social, expressadas em: Como? - Identificando demandas da sociedade e através da cocriação, buscando alcançar resultados que auxiliem a comunidade e ao ambiente; Por que? - O designer pode e deve trabalhar em prol da responsabilidade social, com o intuito de, em seus projetos, tornar melhor a vida das pessoas; Onde? - Pode ser trabalhado em função de definições no setor público, em agências e estúdios de design, nas universidades, ONGs, entre outros; O que? - A prática do design voltado para a sociedade e suas necessidades, buscando um mundo sustentável e igualitário (Figura 1).
Figura 1: Questões para o Design Social. Fonte: Programa Comunidades Criativas das Gerais, 2012.

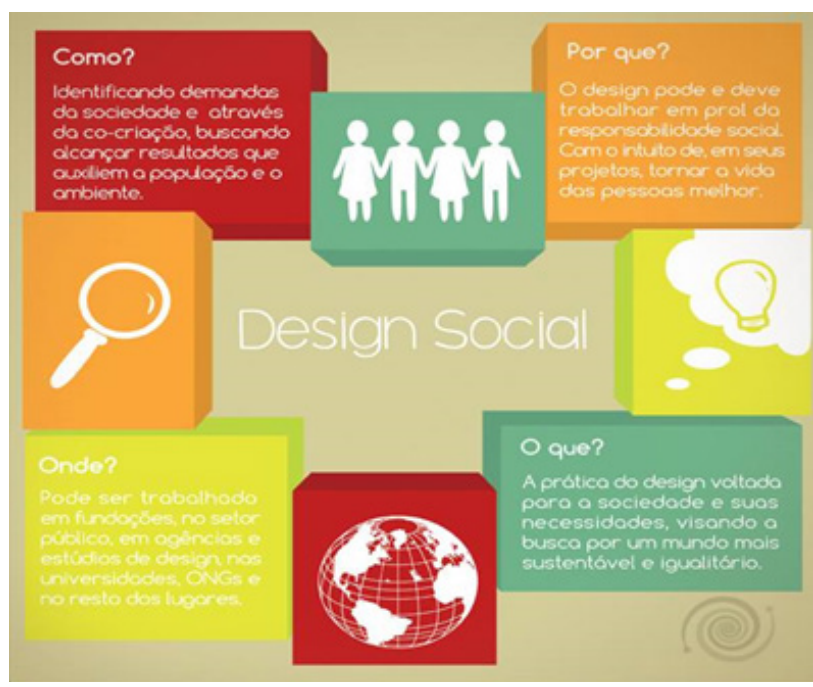

Dessa forma, os designers podem contribuir para um design mais ecológico escolhendo cuidadosamente os materiais que utilizam. O pensamento do design social no mundo do design junta-se ao desenvolvimento humano e ao capital social com novos produtos e processos lucráveis. Estes são fundamentais para a sustentabilidade que serve de base para o bem-estar do ser humano. 


\section{3.}

CULTURA,

IDENTIDADE

EMEMÓRIA
A cultura de uma sociedade é formada pela produção de bens e valores, que através das coordenadas de tempo e espaço caracterizam as identidades de seus membros. A atividade artística, por excelência uma das manifestações culturais mais expressivas de uma sociedade, oferece exemplos dos diferentes modos de percepção e apropriação da realidade. Basta, para tanto, pensar nas incontáveis formas de representação do próprio homem, das inscrições rupestres às atuais expressões virtuais. E é através dessas representações e dos demais objetos e procedimentos de uma comunidade que antropólogos, historiadores da arte, sociólogos e outros estudiosos encontram marcas que permitem caracterizar determinada cultura.

A cultura é a expressão do ser, que se manifesta em todas as suas obras e atividades, é a condição poética do espírito no ato de conformar a matéria. Design, portanto, não é uma atividade protagonista da configuração em um complexo pano de fundo composto por variáveis de natureza política, econômica, social, tecnológica etc., mas, antes, umas das possíveis interpretações das diversas possibilidades oferecidas por estas variáveis.
Design é mais do que a especificação das partes de um todo como na tradição cartesiana. Não é uma regra universal de configuração, mas uma ação interpretativa, criadora, que permite diversas formas de expressão (COELHO, 2008, p.62).

Segundo Laraia (1997), cultura é um contínuo de valores, crenças, costumes, hábitos e fatores históricos materiais e imateriais que pertencem, de forma dinâmica, à vida social. Ou seja, a cultura é erguida ao longo de processos históricos e materiais de um povo, através de suas inter-relações e modos de vida.

Essa concepção de cultura é reforçada por Chaú (2007), que entende a cultura como uma instituição social, sendo determinada pelas edições materiais e históricas de sua realização. Desse modo, a cultura é intrínseca a cada povo, transformando suas experiências tangíveis e intangíveis a partir do trabalho, o qual ultrapassa e modifica algo existente em algo novo. Assim sendo, consente que qualquer povo, independentemente de suas condições materiais e históricas, tenha uma cultura peculiar.

É nessa perspectiva que se compreende a cultura e suas manifestações da realidade, enquanto expressões em nível simbólico, baseado na experiência vivenciada pelos segmentos na sua experiência cotidiana. Nesse sentido, a cultura tanto pode ser expressa por elementos tangíveis como casas, museus, igrejas, entre outros, quanto por aqueles que, ultrapassando uma existência palpável, tornam-se ligações entre a contemporaneidade e um passado socialmente determinado, ou seja, diz respeito a um patrimônio espiritual. 
Segundo Kessing (1974) apud Dornas e Almeida (2013), cultura se divide em duas correntes: 1) aquela que considera cultura como um sistema adaptativo, ou seja, padrões de comportamento sociais transmitidos e adaptados em comunidades humanas de acordo com os estilos de vida; 2) uma teoria idealista dividida em: cultura como sistema cognitivo, ou seja, um sistema de conhecimento: cultura como sistemas estruturais onde se define cultura como um sistema simbólico, que é a criação acumulada da mente humana; e cultura como sistema simbólico onde cultura é um sistema de símbolos e significados compartilhados pelos membros de uma sociedade.

O Brasil possui uma diversidade cultural bem marcante devido ao processo de colonização e às migrações que ocorreram ao longo de sua história. Cada região adquiriu cultura com características e costumes próprios. Porém, o Brasil, assim como outros países, vive um momento de grandes mudanças, em que o limite tempo-espaço está diminuindo cada vez mais, e a aproximação e as misturas culturais são realizadas de forma mais intensa, relacionando-se umas com as outras. Esse acontecimento, denominado globalização, fez do indivíduo um ser multicultural.
4.

PERTENCIMENTO

EO VALOR

SUSTENTÁVEL

DO GUARDAR

E CUIDAR
O homem, quando cercado de objetos pouco tangíveis e imemoráveis, dificilmente é capaz de sentir prazer e felicidade, o que pode levar a uma baixa qualidade de vida. Esvazia-se a emoção da herança, do poder usar e revisar a função e sua ocupação espacial. "Um número excessivo de coisas no mundo são projetadas, construídas e nos são impingidas sem nenhuma compreensão e conhecimento ou mesmo preocupação com relação a como as usamos" (NORMAN, 2006, p. 7).

O processo de valorização da cultura local se dá com a exploração das características regionais e com a participação dos protagonistas da localidade. "Quanto mais a tal da globalização avança trazendo consigo a desterritorialização, mais [...] a gente sente necessidade de pertencer a algum lugar, àquele canto do mundo específico que nos define" (BORGES, 2003, p. 63).

Segundo Bloch (2001), para que um grupo social se "lembre", não basta que os diversos membros que o compõem conservem no espírito as representações que dizem respeito ao passado do grupo. É também necessário que os membros mais velhos cuidem de transmitir essas representações aos mais jovens. Pois o fato é que a memória desaparece quando a história surge. 
Os fatos históricos eram produtos da intervenção ativa do historiador e, desta forma, os estudos da memória coletiva deveriam estar voltados às causalidades inerentes às ações sociais, não podendo ser derivadas de estudos empíricos sobre padrões de comportamentos. A representação do passado, qualquer que seja nunca pode escapar da intervenção ativa de quem a retrata. Assim, o passado se apresenta como um conjunto vivo de representações, que pode ser "uma mentira enquanto tal é o seu modo, um testemunho" (BLOCK, 2001, p.23).

Um dos maiores desafios ao se tratar de estratégias de desenvolvimento sustentável reside exatamente na maneira apropriada de se medir e monitorar resultados. Afinal, a ideia de sustentabilidade expressa a interdependência entre pessoas e o mundo ao redor, buscando a tenacidade de características necessárias e desejadas para as pessoas, as organizações, as comunidades e os ecossistemas em um longo período de tempo ou indefinidamente (HARDI e ZDAN, 1997).

Nesta dimensão emerge já a consciência social do indivíduo. A noção de participação em um ou em vários grupos. Finalmente, neste processo onde podemos analisar a consciência de si do indivíduo, seu valor e sua história, a consciência de sua participação no conjunto social, pode tornar possível a construção de sua bagagem em permanente transformação. Tal ação resulta em crescimento mútuo e na busca por uma sociedade mais igualitária, bem como novas perspectivas de desenvolvimento local sustentável através do design social e da valorização da cultura local.
Os objetos que foram cristalizados pela memória cultural de uma sociedade estão vivos e dinâmicos na nossa contemporaneidade, em múltiplos lugares através de diversos contextos sociais, conscientes ou não das suas funções sociais transformadoras. Os velhos objetos estão afinal vivos, apresentando outras expressões e utilizando outros cenários e outros contextos.

Histórias de vida ricas em valores tangíveis que são rodeados de valores intangíveis, com probabilidade de ser cercados de estórias de um tempo e de um espaço. O que relata Leite (2012) em Olhares Biográficos:

As histórias de vida complementam a "consciência do si" pela análise da "consciência do social". Para a construção das Histórias de Vida importa incorporar não só a narrativa do indivíduo, como, sobretudo interesse confrontar na medida em que se complementa a história contada pela pessoa com toda a panóplia de informação biográfica disponível. [...] Os objetos biográficos transportam a densidade de significados que compõem as diferentes experiências dos sujeitos, as suas expectativas de ação e a natureza relacional onde a interação se processa (LEITE, 2012, p.23). 
5.

ESTUDO DE

CASO: OFICI-

NAS DE MEMÓ-

RIA E PERTEN-

CIMENTO EM

MATOZINHOS
Nesse trabalho foi valorizado essencialmente o processo de interação do grupo focal na construção do pensamento de ação. A metodologia da pesquisa será feita com a análise de imagens, após as revisões bibliográficas, por observação de fotografias de períodos históricos, pois, segundo Weller e Bassalo (2011), imagens são documentos de visões de mundo.

Foi usado também, até o momento, o grupo focal como metodologia qualitativa para esta pesquisa em ciências sociais. Os grupos de foco são particularmente úteis para refletir sobre realidades sociais e culturais, pois através dessa metodologia qualitativa, podemos acender as experiências, significados, entendimentos, assim como as atitudes, opiniões, conhecimentos e crenças (WILKINSON, 1998).

Entretanto, as reflexões sobre o conteúdo social das experiências individuais têm vindo a aprofundar a relação entre as experiências humanas no mundo social e a consciência do indivíduo dessas mesmas experiências através da interação com os objetos pessoais. Através desses objetos acedem à experiência individual e coletiva das comunidades, ao mesmo tempo em que eles fornecem as respostas sobre os possíveis campos de ações de pertencimento.

O tema do sentimento de pertencimento, cada vez mais presente nos estudos culturais na contemporaneidade, é aqui trabalhado na hipótese de que sinaliza, no contexto da sociedade marcada pela busca de valorização da cultura local e sua memória, a busca de identidade através de objetos bibliográficos, segundo aponta Sousa em "O pertencimento ao comum mediático: a identidade em tempos de transição” (2010).

O sentimento de pertencimento se vincula historicamente ao tema de comunidade, no âmbito das ciências humanas e sociais, e hoje ambos são retomados em bases ampliadas de significação e tomam características novas na relação assumida desde décadas passadas na distinção entre comunidade e sociedade. Na verdade, comunidade e sociedade dicotomizaram formas históricas diferentes de compreensão dos processos de socialização, atribuindo-se à primeira a significação nas formas de organização imediata e visível da vida social e cultural e, à segunda, a relação com a racionalidade que sustenta a estrutura da sociedade.

Foram realizadas palestras e oficinas com o objetivo de resgatar o conhecimento e as memórias das comunidades como propostas de ação social de construção de futuro sustentável para as próximas gerações. No primeiro workshop sobre memória e pertencimento, com os moradores do município, realizado em maio de 2015, participaram 40 pessoas, as quais apresentavam idades bem variadas, dos 12 aos 60 anos de 
idade. Havendo referências culturais dispostas no Palácio da Cultura em Matozinhos, questionou-se os moradores e estudantes sobre a existência de conhecimento prévio sobre sua cultura local, sobre o que eles se manifestaram negativamente.

Na Figura 2, registros da Palestra "Memória Cultural" no Palácio da Cultura em Matozinhos, em maio de 2015, com objetivo de sensibilizar e estimular a preservação cultural dos bens tangíveis e intangíveis no cotidiano da comunidade, através da memória social.

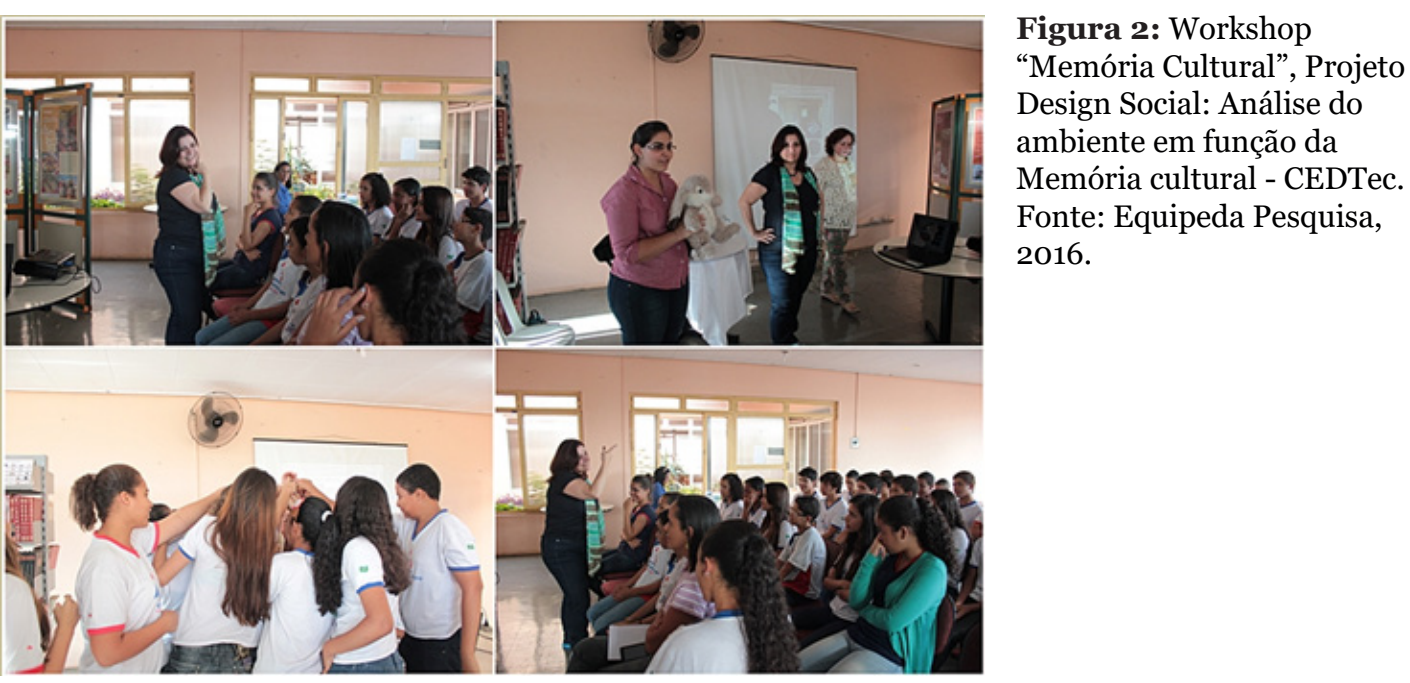

Após a primeira palestra, que possibilitou um contato motivador entre estudantes e moradoras, foram trabalhados os símbolos da memória cultural através de objetos do cotidiano, principalmente brinquedos e brincadeiras infantis, enfatizando costumes da cidade e da região na presença destes objetos no cotidiano dos lares, atendendo assim ao objetivo de resgatar a cultura local proposta no projeto.

Com estas atividades, foi valorizado e resgatado o pertencimento que Bosi (1994) cita:

A criança recebe do passado não só os dados da história escrita mergulha suas raízes na história vivida, ou melhor, sobrevivida, das pessoas de idade que tomaram parte na sua socialização. Sem estas haveria apenas uma competência abstrata para lidar com os dados do passado, mas não a memória. (BOSI, 1994, P.73)

Acredita-se que uma das opções para a reflexão de uma mudança nas relações sociais está no resgate do passado cultural infantil do fazer: brinquedos e brincadeiras. A realidade das pessoas de hoje não é a mesma que os seus antepassados vivenciaram, porém pode-se transformar o momento atual em um momento de prazer, adequando-o aos novos tempos, aos novos espaços, a nova realidade que vive sem perder de vista toda uma cultura tão rica que possibilitou o desenvolvimento pessoal. Se a sociedade desenvolver projetos que invistam neste resgate, se propiciar a oportunidade de interação com objetos simbólicos conseguindo desenvolver atividades prazerosas, sem confrontar "a essência do velho" com "a dinâmica do novo". 
6. CONSIDERAÇÕES FINAIS
Essa análise é de suma importância para os estudos em design, que tem como uma de suas principais preocupações compreender as relações do ser humano com o meio em que vive através da leitura e releitura de objetos biográficos. Lembranças de família e as histórias e possíveis estórias que trazem valores intangíveis para objetos, valores repassados de uma geração à outra que podem promover a melhoria da qualidade de vida das pessoas.

Existem várias bifurcações que o conceito de design para a inovação social vai traçando em meio ao seu caminho. Cada visão traz um diferencial ao design para a inovação social, porém deve-se verificar o sentido onde seja baseada não apenas como uma filosofia de metodologia. O design como projeto será sempre um procedimento para se chegar a um determinado objetivo, no caso de um pensamento social, talvez a iniciativa a ser tomada seja o diferencial.

O pensamento do design para a inovação social no mundo do design junta-se ao desenvolvimento humano e ao capital social com novos produtos e processos lucráveis. Estes são fundamentais para a sustentabilidade que serve de base para o bem-estar do ser humano.
Para que a comunidade conheça sua história, suas características socioculturais e ambientais, são necessárias atividades de planejamento que despertem a atenção da população local.

Os objetos que foram cristalizados pela memória cultural de uma sociedade estão vivos e dinâmicos na nossa contemporaneidade, em múltiplos lugares através de diversos contextos sociais, conscientes ou não das suas funções sociais transformadoras. Os velhos objetos estão afinal vivos, apresentando outras expressões e utilizando outros cenários e outros contextos.

Histórias de vida ricas em valores tangíveis, que são rodeados de valores intangíveis, com probabilidade de ser cercados de estórias de um tempo e de um espaço.

Ainda há muitas vertentes para pesquisas em questões da morada brasileira pelo viés de seus usos e costumes e design. Contudo, buscou-se preservar as relações do homem com seu habitat, por meio da pesquisa local, da discussão e da comunicação, estimulando a inclusão social. 
REFERÊNCIAS BORGES, A. Designer não é personal trainer: e outros escritos. Coleção Textos Design. $2^{\mathrm{a}}$. ed. São Paulo: Rosari, 2003.

BOSI, Ecléa. Memória e Sociedade: lembranças de velhos. São Paulo: Tao, 1979.

BRAGA, Marcos da Costa (org.). O papel social do design gráfico. História, conceitos \& atuação profissional. Edição. 1 ed. São Paulo: Senac, 2011.

CHAUÍ, M. Cultura e Democracia. Coleção Cultura é o quê? Salvador, 2007.

CIPOLLA, Carla. Ambiente do design - design do ambiente: sustentabilidade e inovação. In: MANZINI, Ezio. Design para a inovação social e sustentabilidade. Comunidades criativas, organizações colaborativas e novas redes projetuais. Rio de Janeiro: E-Papers, 2008.

COELHO, Luiz Antônio L. (Org.). Conceitos-chave em design. Rio de Janeiro: Editora PUC Rio, 2008.
GRANBEL. História de Matozinhos. (2011) Postado em: 01 fev. 2011. Disponível em: <http:// www.granbel.com.br/index.php/municipios-metropolitanos/102-municipio-de-matozinhos-municipio-de-matozinhos/159-historia-de-matozinhosmg. html>. Acesso em: 20 mai. 2014.

HARDI, Peter; ZDAN, Terrence. Assessing sustainable development: principles in practice. Winnipeg: IISD, 1997.

IBGE. Matozinhos histórico. biblioteca.ibge.gov. br (2009). Disponível em:< http://biblioteca.ibge. gov.br/visualizacao/dtbs/minasgerais/matozinhos. pdf $>$. Acesso em: 14 nov. 2014.

Informalmuseology.wordpress.com. Disponível em: $<$ http://informalmuseology.wordpres s.com/informal-museology-studies/narrativas-biograficas-e-investigacao-cientifica/as-narrativas-biograficas-oralidade-e-intersubjectividade-em-museologia/> . Acesso em: 28 ago. 2015.

JACÓ-VILELA, A.M., ANDSATO, L. (Orgs.) Diálogos em psicologia social [online]. Rio de Janeiro: Centro Edelstein de Pesquisas Sociais, 2012.

KESSING, Roger. Theories of culture. Camberra: Australian National University, 1974.

KRIPPENDORFF, K. Product Semantics: A Triangulation and Four Design Theories. In: Product Semantics '89 Conference Anais. Helsinki: University of Industrial Arts, 1990. 
LARAIA, R. de B. Cultura: um conceito antropológico. $11^{\mathrm{a}}$ ed. Rio de Janeiro: J. Zahar, 1997.

LEITE, Pedro Pereira. Olhares Biográficos: A Poética da Intersubjetividade em museologia. $1^{\mathrm{a}}$ ed. Lisboa: Marca d'Agua: Publicações e Projetos, 2012.

LÖBACH, B. Design industrial: bases para a configuração dos produtos industriais. São Paulo: Edgar Blusher, 2001.

MANZINI, Ezio. Design para inovação e sustentabilidade: comunidades criativas, organizações colaborativas e novas redes projetuais. Rio de Janeiro: E-papers, 2008.

MARX, C. O Capital: Crítica da Economia Política. Rio de Janeiro: Civilização Brasileira, 1980.

NORMAN, A. Donald. O Design do Dia-a-Dia. Rio de Janeiro RJ: Rocco, 2006.

PAPANEK, Victor. Design para el mundo real. Ecología humana e cambio social. Ediciones Blume. Madrid, 1977.

PLAYGROUNDPROFESSIONALS.COM. (2015). Disponível em: <http://www.playgroundprofessionals.com/magazine/issues/2015/universal-desig$\mathrm{n}$-and-social-equity-our-parks-playgrounds106>. Acesso em: 28 ago. 2015.

SOUSA, Mauro Wilson de. O pertencimento ao comum mediático: a identidade em tempos de transição. Revista Eletrônica de Turismo Cultural, volume 04 - No. 01,1 ${ }^{\circ}$ Semestre de 2010. Disponível em:< http://www.eca.usp.br/Turismocultural.

SUDJIC, Deyan. A linguagem das coisas. Tradução de Adalgisa Campos da Silva. Rio de Janeiro: Intrínseca, 2010

WELLER, W; BASSALO, L. de M. B. Imagens: documentos de visões de mundo. Sociologias, Porto Alegre, ano 13, n. 28, set./dez. 2011. 